\title{
Approaches to Quantifying and Visualizing Polyelectrolyte Multilayer Film Formation on Particles
}

Angus P. R. Johnston, Alexander N. Zelikin, Lillian Lee and Frank Caruso* Centre for Nanoscience and Nanotechnology, Department of Chemical and Biomolecular

Engineering, The University of Melbourne, Victoria 3010, Australia.

\section{Supporting Information}

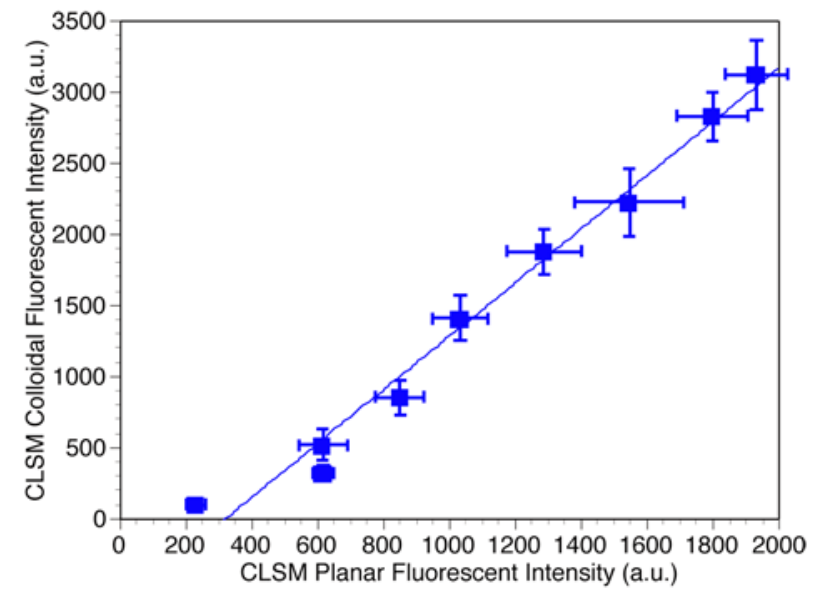

Figure S1. Comparison of the buildup of a $\mathrm{PSS}_{\mathrm{RH}} / \mathrm{PAH}$ multilayer film on planar and particulate $(3 \mu \mathrm{m}$ diameter silica) supports measured after the deposition of the $\mathrm{PSS}_{\mathrm{RH}}$ layer using CLSM.

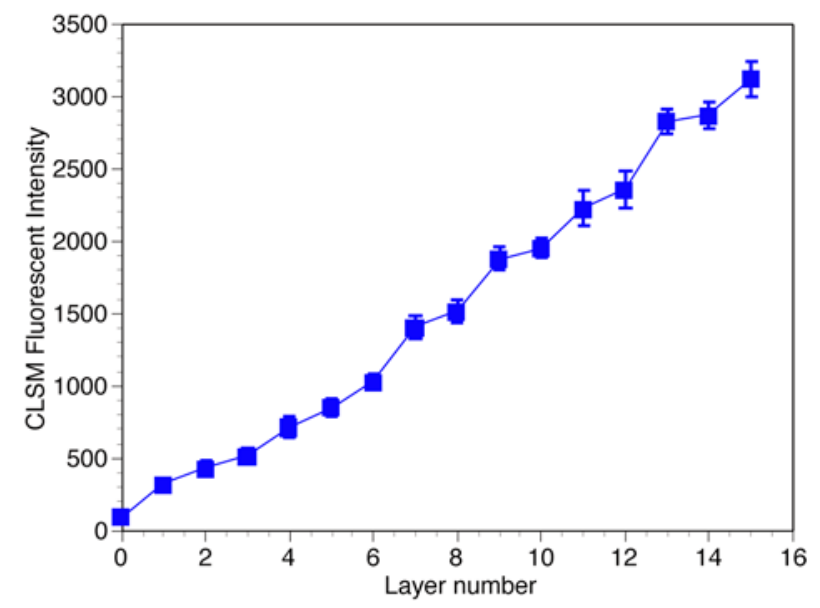

Figure S2. Increase in fluorescence intensity of a $\mathrm{PSS}_{\mathrm{RH}} / \mathrm{PAH}$ multilayer film on $3 \mu \mathrm{m}$ diameter silica particles using CLSM. The odd layers correspond to $\mathrm{PSS}_{\mathrm{RH}}$ and even layers correspond to PAH. 


\section{Calculations}

Calculating adsorbed mass from QCM frequency change.

The change in the QCM frequency can be related to the adsorbed mass using the Sauerbrey equation. For the QCM crystals used, the change in mass is given by the equation:

$$
\Delta F=-0.183 \Delta m
$$

where $m$ is the mass of the film deposited (in $\mathrm{ng} \mathrm{cm}^{-2}$ ) and $F$ is the frequency in $\mathrm{Hz}$

Calculating adsorbed mass from increase in fluorescence intensity.

From the plot of planar CLSM fluorescence vs. QCM frequency (Figure 2), the gradient of the line is 1.65 a.u. $\mathrm{Hz}^{-1}$. Therefore a change in frequency of $100 \mathrm{~Hz}$, corresponds to an increase in fluorescence of 165 a.u. $1 \mathrm{~Hz}$ corresponds to $5.45 \mathrm{ng} \mathrm{cm}$ (gradient $=0.303$ a.u. $\mathrm{ng}^{-1} \mathrm{~cm}^{2}$ ) of adsorbed material, so an increase in film mass of $1 \mu \mathrm{g} \mathrm{cm}^{-2}$ corresponds to 303 a.u.

From the plot of flow cytometry fluorescence intensity vs. particulate CLSM fluorescence intensity (Figure 3), the gradient of the line is 0.25 . As the relationship between CLSM intensity and mass deposited is 0.303 a.u. $\mathrm{ng}^{-1} \mathrm{~cm}^{2}$, the relationship between flow cytometry fluorescence intensity and the mass deposited is 0.0756 a.u ng ${ }^{-1} \mathrm{~cm}^{2}$ (or $13.2 \mathrm{ng} \mathrm{cm}^{-2}$ a.u. $^{-1}$ )

The surface area (S.A.) of a sphere is given by the equation:

$$
S . A .=4 \pi r^{2}
$$

where $r$ is the radius of the particle $\left(1.5 \times 10^{-4} \mathrm{~cm}\right.$ for the $3 \mu \mathrm{m}$ particles and $2.5 \times 10^{-5} \mathrm{~cm}$ for the $500 \mathrm{~nm}$ particles). The surface areas for the $3 \mu \mathrm{m}$ and $500 \mathrm{~nm}$ diameter particles are $2.8 \times 10^{-7} \mathrm{~cm}^{2}$ and $7.8 \times 10^{-9}$ $\mathrm{cm}^{2}$, respectively.

For a $3 \mu \mathrm{m}$ diameter particle, with surface area of $2.8 \times 10^{-7} \mathrm{~cm}^{2}$, the absolute mass change per a.u. is calculated by multiplying $13.2 \mathrm{ng} \mathrm{cm}^{-2}$ a.u. ${ }^{-1}$ by the surface area of the particle. This corresponds to 3.7 fg a.u..$^{-1}$.

\section{Correcting the fluorescence intensity measured at $900 \mathrm{~V}$ compared with $600 \mathrm{~V}$.}

The fluorescence intensity of the $3 \mu \mathrm{m}$ particles was acquired on the flow cytometer with a PMT voltage of $600 \mathrm{~V}$ (as outlined in the experimental section). Due to the lower fluorescence intensity of the $500 \mathrm{~nm}$ particles, the PMT voltage was increased to $900 \mathrm{~V}$. To directly compare the fluorescence intensity of both particles, the fluorescence intensity of the $500 \mathrm{~nm}$ particles was divided by the factorial increase associated with increasing the PMT voltage from $600 \mathrm{~V}$ to $900 \mathrm{~V}$. The factorial increase was measured using Spherotech 8 - peak rainbow calibration particles - a solution of 8 different particles, which contain a known amounts of fluorophore. The increase in fluorescence intensity of particles with the second, third and fourth least fluorophore were compared, as these were the only particles that were on scale for measurements at both $600 \mathrm{~V}$ and $900 \mathrm{~V}$. The change in fluorescence intensity is shown in Table 1.

\begin{tabular}{|c|c|c|c|}
\hline \multicolumn{3}{|c|}{ Table 1 - Increase in Fluorescence Intensity with Change in PMT Voltage } \\
\hline \multirow{2}{*}{ Peak Number } & \multicolumn{2}{|c|}{ Fluorescence Signal } & Increase Factor \\
\cline { 2 - 3 } & at 600 V & at 900 V & \\
\hline 2 & 30 & 642.9 & 21.43 \\
\hline 3 & 72.8 & 1612.9 & 22.16 \\
\hline 4 & 249.7 & 5180.5 & 20.75 \\
\hline \multicolumn{3}{|c}{ Average Increase Factor } & 21.44 \\
\hline
\end{tabular}

From this information, the increase in fluorescence intensity by increasing the PMT voltage from 600 $\mathrm{V}$ to $900 \mathrm{~V}$ is 21.44 .

Therefore, if the relationship between mass deposited and fluorescence intensity is $3.7 \mathrm{fg}$ a.u. ${ }^{-1}$ at 600 $\mathrm{V}$, at $900 \mathrm{~V}$ the relationship between mass deposited and fluorescence intensity is $0.17 \mathrm{fg} \mathrm{a.u.}{ }^{-1}$.

To normalise the surface area of $500 \mathrm{~nm}$ diameter particles to the surface area of the $3 \mu \mathrm{m}$ diameter particles, the corrected fluorescence intensity of the $500 \mathrm{~nm}$ diameter particles was multiplied by 36 , because the surface are of the $500 \mathrm{~nm}$ particles is $1 / 36^{\text {th }}$ that of $3 \mu \mathrm{m}$ particles. $500 \mathrm{~nm}$ particles are $1 / 6^{\text {th }}$ the radius of $3 \mu \mathrm{m}$ particles $\left(\frac{250}{1500}=\frac{1}{6}\right)$, and $S . A . \propto r^{2}$, therefore $S . A . \propto\left(\frac{1}{6}\right)^{2} \propto \frac{1}{36}$. 